\title{
New onset systemic lupus erythematosus in a patient receiving etanercept for rheumatoid arthritis
}

\author{
A P Cairns, M K J Duncan, A E Hinder, A J Taggart
}

Ann Rheum Dis 2002;61:1031-1032

$\mathrm{T}$ he management of severe rheumatoid arthritis (RA) has been revolutionised by the introduction of the biological agents infliximab (Remicade-a chimeric anti-tumour necrosis factor (TNF) $\alpha$ antibody), and etanercept (Enbrel-a soluble TNF $\alpha$ receptor). Both these agents lower the effective level of $\mathrm{TNF} \alpha$, and have been shown to be effective in the management of active RA, either alone (etanercept) or in combination with methotrexate (infliximab). ${ }^{12}$ Full blown drug-induced systemic lupus erythematosus (SLE) has been reported with infliximab, ${ }^{3}$ but not (until very recently) with etanercept, ${ }^{4}$ although antinuclear antibodies and autoimmune skin rashes have been reported with etanercept. ${ }^{56}$ We report a case of new onset SLE in a patient receiving etanercept.

\section{CASE REPORT}

Treatment of a 51 year old woman with severe seropositive erosive RA with methotrexate, sulfasalazine, Myocrisin (sodium aurothiomalate), D-penicillamine, hydroxychloroquine, and leflunomide had previously failed and she continued to require repeated courses of systemic corticosteroids to control her disease. She started etanercept, receiving twice weekly doses of $25 \mathrm{mg}$ subcutaneously, and achieved a good clinical response, with a significant reduction in disease activity scores. Other drugs taken were meloxicam and cocodamol. The etanercept was withheld for a total of four weeks during an intercurrent chest infection, but no other side effects were noted until after seven months of etanercept treatment.

At this stage the patient developed a photosensitive "burning" rash on the exposed areas of her face, neck, and arms. She felt generally lethargic, and described Raynaud's phenomenon. She had clinically active synovitis. There was no evidence of sepsis. An antinuclear antibody test, which had previously been negative, was now strongly positive (titre 1 in 320 by indirect immunofluorescence on rat liver sections), and dsDNA antibodies were present $(9.2 \mathrm{mg} / \mathrm{l}$ by the Farr assay) (normal range 0-8). Antinucleosome antibodies were strongly positive by enzyme linked immunosorbent assay (ELISA; Organtec) at $180 \mathrm{U} / \mathrm{ml}$ (normal range $0-20 \mathrm{U} / \mathrm{ml}$ ). Total white cell count had fallen to $1.62 \times 10^{9} / 1$ (neutrophils 0.58 , lymphocytes 0.88). Haemoglobin and platelet counts were normal. Vasculitic screen was negative, while rheumatoid factor remained positive. There was a polyclonal rise in immunoglobulins, and erythrocyte sedimentation rate was raised ( $46 \mathrm{~mm} / \mathrm{lst} \mathrm{h}$ ). Renal and liver function tests were normal.

A diagnosis of SLE was made and her etanercept was discontinued. She received three intramuscular injections of triamcinolone $40 \mathrm{mg}$ over three weeks, and treatment with prednisolone $10 \mathrm{mg} /$ day and alendronate $70 \mathrm{mg} /$ week was started. Three weeks after stopping etanercept and starting corticosteroids the rash had completely disappeared, the patient was feeling generally better. The synovitis had also improved. After three months the total white cell count had increased to $3.63 \times 10^{9} / 1$ (neutrophils 2.21 , lymphocytes 1.07 ). A yellow card reporting this probable drug reaction was completed.

\section{DISCUSSION}

We have described the new onset of SLE in a patient receiving etanercept for RA. Before receiving etanercept the patient had, on a number of occasions, had a total white cell count between 2.5 and $4 \times 10^{9} / 1$ (normal range 4-11). An ultrasound scan of the abdomen had shown a mild degree of splenomegally of normal consistency in keeping with Felty's syndrome. There were no other prior features of SLE. In particular, antinuclear antibody and anti-double stranded DNA antibody tests were negative (on two separate occasions), there was no history of rash or photosensitivity, and no history of renal or neurological disease. The improvement in symptoms, signs, and white cell count on stopping the etanercept would be in keeping with a case of drug-induced SLE. The alternative explanation is that the pre-existing leucopenia was a manifestation of a pre-existing lupus-like disease which was unmasked by the etanercept. This would be supported by occasional preetanercept episodes of lymphopenia, which is less common in Felty's syndrome.

Why should TNF $\alpha$ blocking therapy cause or unmask SLE? One possible explanation is that TNF $\alpha$ may up regulate the cellular expression of the adhesion molecule CD44, which has a role in the clearance of apoptotic neutrophils by phagocytes. $^{78}$ Impaired clearance of apoptotic cells, and reduced leucocyte CD44 expression, have been described in SLE. ${ }^{10}$ This is, however, a complex area which requires clarification by further study. There is no doubt that etanercept and infliximab represent great advances in the treatment of RA. This case serves to illustrate that patients receiving these drugs should be closely monitored, and caution exercised in any patient with lupus-like or leucopenic disease features.

\section{Authors' affiliations}

A P Cairns, M K J Duncan, A E Hinder, A J Taggart, Department of Rheumatology, Musgrave Park Hospital, Belfast, Northern Ireland, UK

Correspondence to: Dr A Cairns, Department of Rheumatology, Musgrave Park Hospital, Stockman's Lane, Belfast BT9 7JB, Northern Ireland, UK; andrewcairns@doctors.org.uk

Accepted 27 March 2002

\section{REFERENCES}

1 Bathon JM, Martin RW, Fleischmann RM, Tesser JR, Schiff MH, Keystone $\mathrm{EC}$, et al. A comparison of etanercept and methotrexate in patients with early rheumatoid arthritis. N Engl J Med 2000;343:1586-93.

2 Lipsky PE, van der Heijde DM, St Clair EW, Furst DE, Breedveld FC, Kalden JR, et al. Infliximab and methotrexate in the treatment of rheumatoid arthritis. Anti-tumor necrosis factor trial in rheumatoid arthritis with concomitant therapy study group. N Engl J Med 2000;343:1594602.

3 Charles PJ, Smeenk RJ, De Jong J, Feldmann M, Maini RN. Assessment of antibodies to double-stranded DNA induced in rheumatoid arthritis patients following treatment with infliximab, a monoclonal antibody to 
tumor necrosis factor alpha: findings in open-label and randomized placebo-controlled trials. Arthritis Rheum 2000;43:2383-90.

4 Shakoor N, Michalska M, Harris CA, Block JA. Drug-induced systemic lupus erythematosus associated with etanercept therapy. Lancet 2002:359:579-80

5 Brion PH, Mittal-Henkle A, Kalunian KC. Autoimmune skin rashes associated with etanercept for rheumatoid arthritis. Ann Intern Med $1999 ; 131: 634$

6 Bleumink GS, ter Borg EJ, Ramselaar CG, Ch Stricker SB.

Etanercept-induced subacute cutaneous lupus erythematosus. Rheumatology (Oxford) 2001;40:1317-19.

7 Osada A, Nakashima H, Furue M, Tamaki K. Up-regulation of CD44 expression by tumor necrosis factor-alpha is neutralized by interleukin-10 in Langerhans cells. J Invest Dermatol 1995:105:124-7.

8 Hart SP, Dougherty GJ, Haslett C, Dransfield I. CD44 regulates phagocytosis of apoptotic neutrophil granulocytes, but not apoptotic ymphocytes, by human macrophages. J Immunol 1997;159:919-25.

9 Herrmann M, Voll RE, Zoller OM, Hagenhofer M, Ponner BB, Kalden JR. Impaired phagocytosis of apoptotic cell material by monocyte-derived macrophages from patients with systemic lupus erythematosus. Arthritis macrophages from patients

10 Cairns AP, Crockard AD, McConnell JR, Courtney PA, Bell AL. Reduced expression of CD44 on monocytes and neutrophils in systemic lupus erythematosus: relations with apoptotic neutrophils and disease activity. Ann Rheum Dis 2001;60:950-5.

\title{
Biochemical and morphological study of human articular chondrocytes cultivated in the presence of pulsed signal therapy
}

\author{
A Fioravanti, F Nerucci, G Collodel, R Markoll, R Marcolongo
}

Ann Rheum Dis 2002;61:1032-1033

$\mathrm{P}$ ulsed signal therapy (PST) is an extension of pulsed electromagnetic fields (PEMF) therapy. PEMF have been used widely to treat non-healing fractures and related problems in bone healing since approval by the Food and Drug Administration in 1979. ${ }^{12}$ Recently, PEMF therapy has been used to treat patients with osteoarthritis (OA) of the knee and cervical spine, with encouraging results. ${ }^{34}$ In vitro studies have also shown a stimulating activity of PEMF on cartilaginous metabolism.

PST, in contrast with PEMF, uses specific physiological changing rectangular pulses as stimuli, which are transmitted in a programmed alternating fashion that mimics the body's natural streaming potentials for one hour of treatment.

We studied the effects of PST on human OA chondrocytes cultivated in the presence and absence of a negative stimulus represented by interleukin $1 \beta$ (ILl $\beta$ ) and we evaluated the concentration of proteoglycans (PGs) in the culture medium and the morphology of the chondrocytes after exposure to PST.

Human OA chondrocytes were cultivated in alginate gel on Petri dishes for 72 hours with and without ILl $\beta(5 \mathrm{ng} / \mathrm{ml})$. Some dishes were exposed to PST for three hours a day. ${ }^{5}$ The PST stimulation was administered by a device constructed for in vitro study. This apparatus has suitable dimensions for insertion in a $\mathrm{CO}_{2}$ incubator. The device produces extremely low frequency (less than $30 \mathrm{~Hz}$ ) varying pulsed electromagnetic fields averaging 10-20 G of magnetic energy at a coil current of up to 2 A drawn from a power source of $120 \mathrm{~V} \mathrm{AC.}$ The pulse phase duration was $67 \mathrm{~ms}$, including 15 micropulses with a pause duration of $0.1 \mathrm{~s}$.

Control cultures were maintained under identical conditions but in the absence of PST. After the culture period the medium was removed and collected for determination of the PGs by an immunoenzymatic method on microplates for the quantitative measurement of human PGs. ${ }^{6}$ Cells in alginate gel were immediately fixed for transmission electron microscopy (TEM) and for scanning electron microscopy (SEM). For each different experimental condition we observed 50 cells for TEM and 100 cells for SEM.

Table 1 shows the PG concentration in the culture medium at baseline, in the presence of ILl $\beta$, and with and without PST stimulation. The presence of ILl $\beta$ produced a significant decrease $(p<0.05)$ in PG levels, but when the cells were cultured in the presence of ILl $\beta$ and given PST stimulation, PG
Table 1 PG concentration (ng/ug DNA) in culture medium in various experimental conditions. The data are expressed as the mean (SD) of PG release into the culture medium per microgram of DNA in the eight tested cultures.

\begin{tabular}{llll}
\hline Basal & IL1 & Basal PST & IL1 PST \\
\hline $435.9(282.7)$ & $208.9(93.8)^{*}$ & $458.4(259.3)$ & $365(210.7)^{*}$
\end{tabular}

Student's $t$ test was used for statistical analysis.

${ }^{*} \mathrm{p}<0.05$, ILI $v$ basal and ILI PST $v$ ILI.

production was significantly restored $(\mathrm{p}<0.05)$. The results for metabolic production are further confirmed by the morphological findings obtained by TEM (fig 1) and SEM analysis (data not shown). TEM analysis showed that ILI $\beta$ causes marked cellular damage, confirmed by the presence of several vacuoles in the cytoplasm, which is devoid of typical structures (fig lB). When the cells were cultured in the presence of ILI $\beta$ and given PST stimulation, the cell structures were clearly restored (fig 1D).

These experiments confirm the negative effect of ILI $\beta$ on PG production. ${ }^{6-8}$ Exposure of the chondrocytes to PST significantly restored the PG concentration in the culture medium. Such a resumption of anabolic activity was confirmed by morphological observations obtained by TEM and SEM analyses. The PST signals create a "streaming potential" of ionic flow similar to that generated in a moving joint, and thus they stimulate the anabolic activity of chondrocytes.

Our results are supported by numerous in vitro and in vivo observations, such as electric stimuli and PEMF enhanced cartilage repair processes. External oscillating electric fields increased the incorporation of $\left[{ }^{3} \mathrm{H}\right]$ thymidine into the DNA of chondrocytes isolated from embryonic chick epiphyses, and capacitatively coupled electric fields stimulated cell proliferation $\left(\left[{ }^{3} \mathrm{H}\right]\right.$ thymidine incorporation) and glycosaminoglycan synthesis $\left({ }^{35} \mathrm{SO}_{4}\right.$ uptake) by isolated bovine growth plate chondrocytes. ${ }^{910}$ One mechanism suggested for the actions of these electric and magnetic stimuli is an effect on charged transmembrane molecules, such as receptors. ${ }^{9}{ }^{10}$ Furthermore, electromagnetic fields cause a movement of calcium and other ions across cell membranes and stimulate DNA transcription, resulting in increased protein synthesis. ${ }^{910}$ 

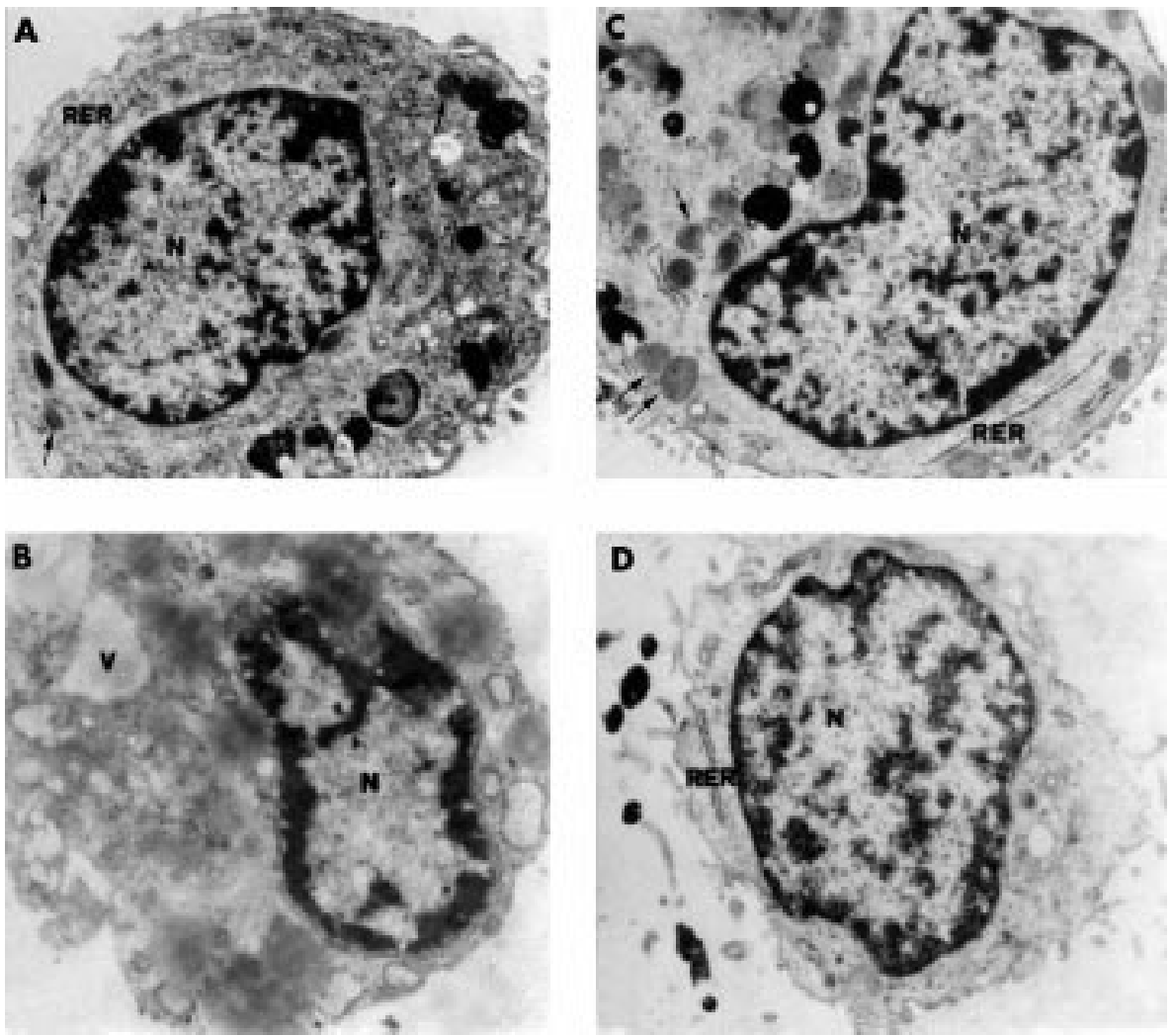

Figure 1 Transmission electron micrographs of chondrocytes cultured in vitro for 72 hours. (A) Basal conditions: the nucleus (N) appears euchromatic, the cytoplasm contains abundant rough endoplasmic reticulum (RER) and lipid droplets (arrows). $\times 9000$. (B) IL1 $\beta$ present: the cell shows a vacuolate cytoplasm devoid of the typical structure. $N$, nucleus; $V$, vacuole. $\times 9000$. (C) Basal conditions and given PST stimulation: the cell shows an euchromatic nucleus (N) and a cytoplasm rich in rough endoplasmic reticulum (RER) and lipid droplets (arrows). $\times 10000$ (D) ILI $\beta$ present and given PST stimulation: the cell clearly recovers its good state of health. Rough endoplasmic reticulum (RER) is present and vacuoles are almost absent. $\mathrm{N}$, nucleus. $\times 9000$.

Our study has confirmed, for the first time, the effect of PST on human chondrocytes cultured in alginate gel. The observed increased concentration of PGs in the culture medium, supported by ultrastructural and morphological analyses by TEM and SEM, confirmed the stimulating activity of this "non-pharmacological treatment" on chondrocytes. Further in vitro and in vivo studies are necessary to verify the effects and the mechanism of action of PST.

\section{Authors' affiliations}

A Fioravanti, F Nerucci, R Marcolongo, Institute of Rheumatology, University of Siena, Siena, Italy

G Collodel, Department of General Biology and Centre for the Study of Germinal Cells, CNR, Siena, Italy

R Markoll, Bio-Magnetic Therapy Systems, Inc, Boca Raton, Florida 33432, USA and Munich, Germany

Correspondence to: Dr A Fioravanti, Istituto di Reumatologia dell'Università di Siena, Policlinico "Le Scotte", I-53100 Siena, Italy;

Accepted for publication 16 April 2002

\section{REFERENCES}

1 Bassett C, Valdes M, Hernandez E. Modification of fracture repair with selected pulsing electromagnetic fields. J Bone Joint Surg Am 1982;64:888-95.
2 Lunt MJ, Barker AT. Pulsed magnetic field therapy for tibial non-union and for rotator cuff tendinitis. Lancet 1984;i: 1289-95.

3 Trock DH, Bollet A, Markoll R. The effect of pulsed electromagnetic fields in the treatment of osteoarthritis of the knee and cervical spine. Report of randomized, double blind, placebo controlled trials. J Rheumatol 1994;21:1903-11

4 Markoll R. Pulsed signal therapy for the treatment of osteoarthritis: double blind and randomized study results in over 50,000 patients [abstract]. Ann Rheum Dis 2000;59(EULAR suppl I): 131.

5 Liu H, Abbott J, Bee JA. Pulsed electromagnetic fields influence hyaline cartilage extracellular matrix composition without affecting molecular structure. Osteoarthritis Cart 1996;4:63-76.

6 Nerucci F, Fioravanti A, Cicero MR, Collodel G, Marcolongo R. Effects of chondroitin sulfate and interleukin-1 $\beta$ on human chondrocyte cultures exposed to pressurization: a biochemical and morphological study. Osteoarthritis Cart 2000; 8:279-87.

7 Beekman B, Verziil N, De Roos JADM, Tekoppele JM. Matrix degradation by chondrocytes cultured in alginate: IL-1 $\beta$ induces proteoglycan degradation and proMMP synthesis but does not result in collagen degradation. Osteoarthritis Cart 1998:6:330-40.

8 Yaron I, Meyer FA, Dayer JM, Bleiberg I, Yaron M. Some recombinant human cytokines stimulate glycosaminoglycan synthesis in human synovial fibroblast cultures and inhibit it in human articular cartilage culture. Arthritis Rheum 1989;32:173-80.

9 Rodan GA, Bourret LA, Norton LA. DNA synthesis in cartilage cells is stimulated by oscillating fields. Science 1978;199:690-2.

10 Armstrong PF, Brighton CT, Star AM. Capacitively coupled electrical stimulation of bovine growth plate chondrocytes grown in pellet form. Orthop Res 1988;6:265-71. 


\title{
Ultrasonographic diagnosis of de Quervain's tenosynovitis
}

\author{
M Kamel, K Moghazy, H Eid, R Mansour
}

de Quervain's disease is a stenosing tenosynovitis. There is inflammation of the cellular lining membrane of fibrous tube through which the tendons of abductor pollicis longus and extensor pollicis brevis move, at the radial styloid process beneath the flexor retinaculum. The disease may occur in rheumatoid arthritis, other inflammatory synovitides, and pregnancy. Patients have considerable pain and a weak hand grip.

\section{PATIENTS AND METHODS}

We investigated the value of ultrasonography in the diagnosis of de Quervain's tenosynovitis and monitored the changes in tendon sheath after ultrasound guided local steroid injection. Twenty one patients with a clinical diagnosis of de Quervain's

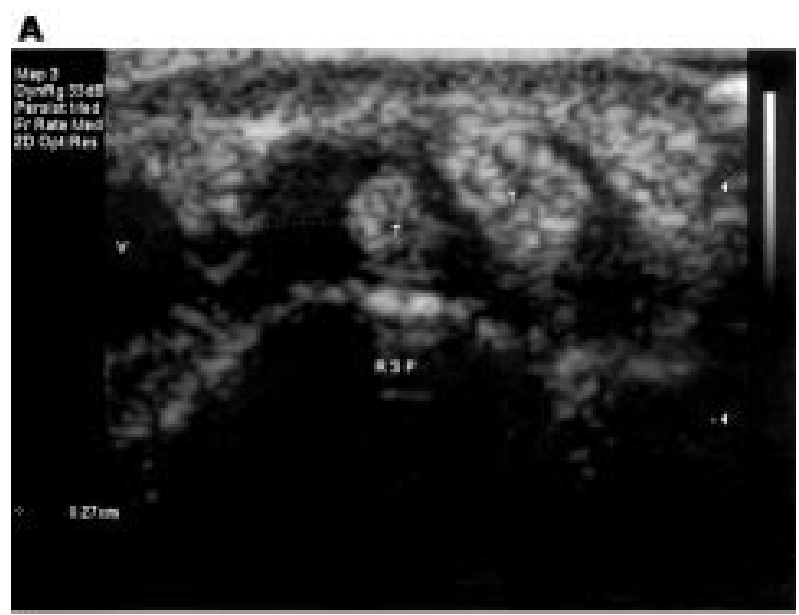

B

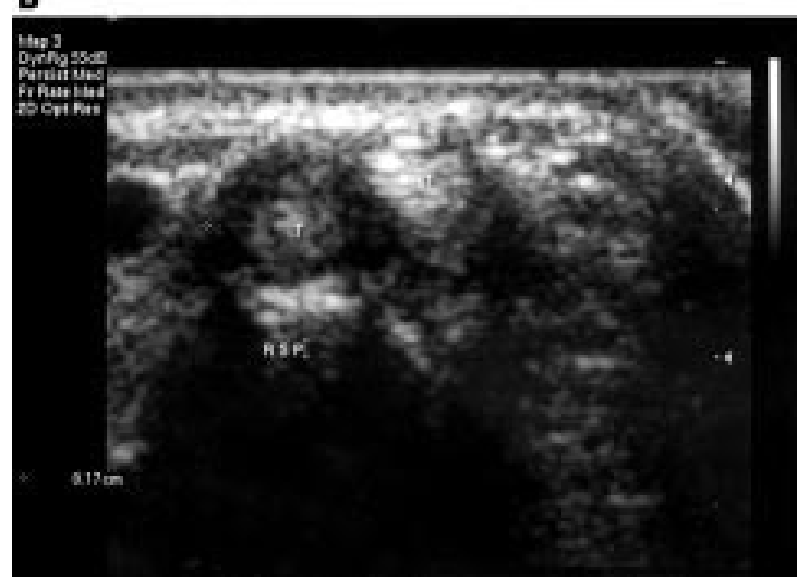

Figure 1 (A) Ultrasonographic transverse image of the symptomatic tendons of the abductor pollicis longus and the extensor pollicis brevis, showing a diffuse circumferential hypoechoic thickening of the synovial sheath $(0.27 \mathrm{~cm})$, giving a characteristic double target pattern, denoting de Quervain's tenosynovitis; (B) ultrasound transverse scans of the same patient. After one week of injection, note the decrease in thickening of the synovial sheath $(0.17 \mathrm{~cm})$. T, tendon; RSP, radial styloid process. $11 \mathrm{MHz}$. tenosynovitis and 10 healthy subjects were studied prospectively. We used a visual analogue scale (VAS) 0-10 and grip strength to measure pain.

The ultrasound examination was performed using an HDI 3000 from ATL (USA) with an $11 \mathrm{MHz}$ linear array transducer. The marginal appearance of the tendon sheath in the transverse and longitudinal scans was examined and measured.

\section{RESULTS AND DISCUSSION}

The ultrasound longitudinal scan of the symptomatic tendon showed distension in the tendon sheath with a surrounding fluid film giving the appearance of diffuse circumferential hypoechogenicity. The transverse scan of the tendon showed a double target pattern (fig 1A).

Several studies have shown that ultrasound is a reliable and sensitive method for detecting tenosynovitis. ${ }^{1-5}$ This study on de Quervain's tenosynovitis clearly detected structural changes, even minimal tendon abnormalities, tendon inner structure, tendon thickening, effusion, and paratendinitis. The affected tendons were inflamed and thickened and showed a significantly increased thickness compared with normal subjects (fig lA).

The affected tendon sheath was infiltrated with a combination of $15 \mathrm{mg}$ triamcinolone diacetate and $2 \mathrm{ml}$ of $2 \%$ lidocaine. After carefully identifying the area of the diseased tendon, the ultrasound guided 23"gauge needle was inserted through the sterile skin at the radial styloid process and advanced anteriorly and slightly downwards in a direction parallel to the tendon. The insertion of the needle into the tendon sheath and delivery of the therapeutic agents were done under direct sonographic visualisation. An ultrasound examination was performed after clinical evaluation and repeated immediately after infiltration of the therapeutic agents, then 1, 6 and 12 weeks later.

A significant decrease in the thickness of the tendon sheath was seen one week after the local corticosteroid injection, Complete relief of symptoms and signs was further observed at 6 and 12 weeks (fig 1B). No complications after injection were reported. The VAS $0-10$ scale and hand grip strength were significantly improved after the local injection $(\mathrm{p}<0.001)$.

Recently, ultrasound has been used to direct the needle in delivering therapeutic agents into joints and enthesial sites with more accuracy. ${ }^{6-8}$ Ultrasonography allows safe and correct placement of needles and injection of drugs into the tendon sheath. Ultrasonography helps to establish the exact location of the inflammation and directs delivery of the drug into the correct target by direct sonographic visualisation. ${ }^{69}$ Therefore, this technique is cost effective in daily rheumatology practice. It also minimises the risk of iatrogenic damage and prevents intratendinous injection of the therapeutic materials. ${ }^{7-10}$

Our ultrasonographic study showed that the local steroid treatment was significantly effective in reducing pain and the amount of increased thickness and swelling of the tendons of the abductor pollicis longus and extensor pollicis brevis within a week after the injection. It was shown clinically to produce longlasting reversal of inflammation in the patients, as was demonstrated by the ultrasound examination follow up at weeks 1,6 , and 12 . 
We believe that ultrasound has both diagnostic and therapeutic value in the daily practice of rheumatology. The ultrasound technique is readily reproducible and helps to confirm the clinical diagnosis and treatment of de Quervain's tenosynovitis.

\section{Authors' affiliations}

M Kamel, Al-Azhar University, Cairo, Egypt; and Dr Fakhry-Al-Mouhawis Hospital, Al-Khobar, Saudi Arabia

K Moghazy, Alexandria University, Egyp

H Eid, Menofyia University, Egypt

R Mansour, Dr Fakhry-Al Mouhawis Hospital, Al-Khobar, Saudi Arabia

Correspondence to: Dr M Kamel, Dr Fakhry-Al Mouhawis Hospital, PO Box 251, Al-Khobar, Saudi Arabia; mkamel56@hotmail.com

Accepted 27 March 2002

\section{REFERENCES}

1 Grassi W, Filippucci E, Farina A, Cervini C. Sonographic imaging of tendons. Arthritis Rheum 2000;43:969-76.
2 Wakefield RJ, Gibbon WW, Emery P. The current status of ultrasonography in rheumatology. Rheumatology (Oxford) 1999;38:195-201.

3 Backhaus M, Kamradt T, Sandrock D, Loreck D, Fritz J, Wolf KJ, et al. Arthritis of the finger joints: a comprehensive approach comparing conventional radiography, scintigraphy, ultrasound, and contrast-enhanced magnetic resonance imaging. Arthritis Rheum 1999;42:1232-45

4 Kamel $\mathrm{M}$, Kotob $\mathrm{H}$. Identification and prevalence of rheumatoid nodules in the finger tendons using high frequency ultrsonography. J Rheumatol $1999 ; 26: 1264-8$

5 Grassi W, Lamanna G, Farina A, Cervini C. Synovitis of small joints: sonographic-guided diagnostic and therapeutic approach. Ann Rheum Dis 1999:58:595-7.

6 Koski JM. Ultrasound guided injections in rheumatology. J Rheumatol 2000;27:2131-8.

7 Kamel M, Kotob H. Ultrasonographic assessment of local steroid injection in Tietze's syndrome. Br J Rheumatol 1997:36:547-50.

8 Kamel M, Kotob H. Ultrasonographic assessment of local steroid injection in plantar fasciitis. Arthritis Rheum 1997;40:1370.

9 Kamel $M$, Kotob H. High frequency ultrasonographic findings in planter fasciitis and assessment of local steroid injection. J Rheumato 2000:27:2139-41.

10 Kamel M. Ultrasonographic assessment of local steroid injection in de Quervain's tenosynovitis [abstract]. Arthritis Rheum 2000;43.

\title{
Diagnosis of Takayasu's arteritis by unexpected findings on abdominal CT scan
}

\author{
A Muthumala, D S Appleton, J S H Gaston
}

W report the case of a 30 year old woman with atypical presentation of Takayasu's disease in whom the diagnosis was first made by an abdominal computed tomography (CT) scan.

\section{CASE REPORT}

A 30 year old woman was admitted for investigation of an eight month history of lower abdominal pain. The pain was cramping in character, preceded bowel motions, and radiated to the back. She also had a four year history of general malaise with fleeting arthralgias and myalgias, and persistently raised inflammatory markers had been noted. Past medical history included alopecia, occasional mouth ulcers, and pulmonary embolism two years previously. Both her father and paternal grandfather had died of "ruptured aortic aneurysms". Previous investigation of her abdominal pain at another hospital with an ultrasound scan had shown a small scarred right kidney.

On examination she was apyrexial, with a regular radial pulse of 84 beats/min and blood pressure of 120/70 $\mathrm{mm} \mathrm{Hg}$ in both arms. There was a soft ejection systolic murmur which radiated to the neck. All peripheral pulses were palpable. Abdominal examination showed mild right iliac fossa tenderness with no guarding. Examination of the respiratory and nervous systems (including fundoscopy) were unremarkable. Investigations showed a raised erythrocyte sedimentation rate (ESR) of $88 \mathrm{~mm} / \mathrm{lst} \mathrm{h}$ and raised C reactive protein (CRP) of $77 \mathrm{mg} / \mathrm{l}$. Perinuclear antineutrophil cytoplasmic antibodies
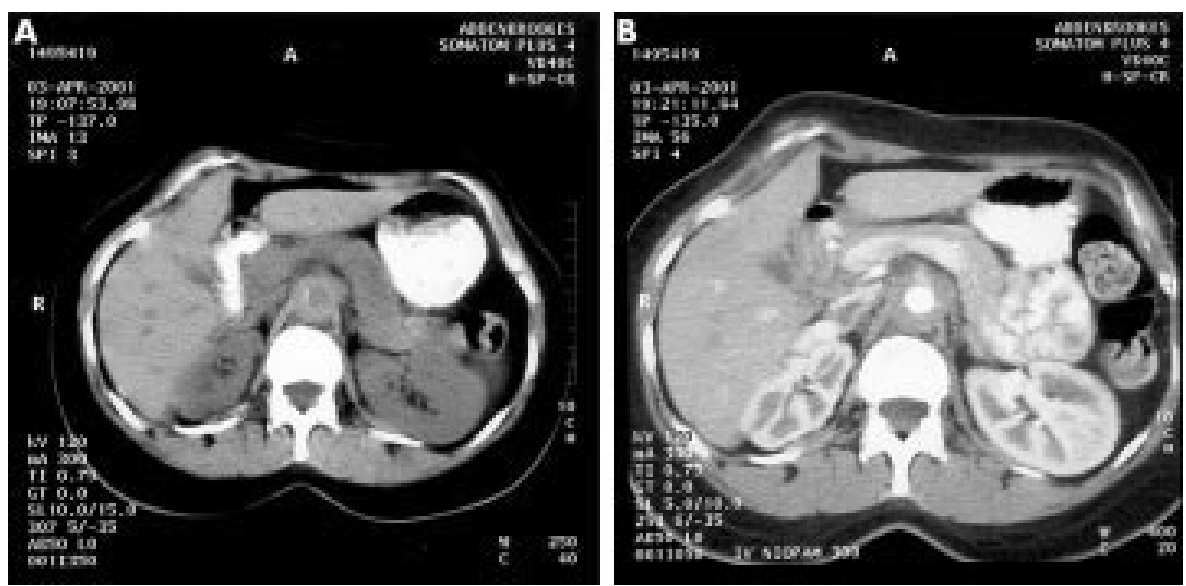

Figure 1 Abdominal CT scan without (A) and with (B) contrast medium. Note the thickening of the aortic wall on both images, with evidence of intimal calcification (A) and the encasement of the origin of the coeliac axis (B). 
were demonstrated by immunofluorescence, but enzyme linked immunosorbent assay (ELISA) measurements of antibodies to myeloperoxidase and proteinase 3 were normal. Serum angiotensin converting enzyme and complement levels were normal; rheumatoid factor and antinuclear antibodies were negative. An echocardiogram showed mild aortic regurgitation and a slightly dilated ascending aorta, but normal cardiac function.

To investigate the abdominal pain further abdominal CT scanning was performed. This showed a normal gastrointestinal tract, but was remarkable for diffuse thickening of the abdominal aortic wall and narrowing of the aortic lumen (fig 1). Image A also shows some evidence of calcification of the intima. Administration of intravenous contrast showed that the aortic wall was $\sim 1 \mathrm{~cm}$ thick. Image $\mathrm{B}$ shows encasement of the origin of the coeliac axis. As well as aortitis, this thickening might possibly represent periaortitis.

On re-examination of the patient bilateral renal bruits were noted. In view of the history of prominent inflammatory symptoms - malaise, arthralgias, myalgias; symptoms suggestive of vessel involvement-abdominal aortic narrowing causing ischaemic pain; and the physical examination, a diagnosis of Takayasu's arteritis was considered. This was confirmed by aortography which, as well as showing the dilated ascending aorta and the narrowed abdominal aorta, also demonstrated stenoses of both subclavian and proximal renal arteries. Small aneurysms of the third and fourth order branches of the right renal artery were seen.

She was treated with pulsed intravenous methylprednisolone and discharged on oral prednisolone. After two weeks the patient reported that her pain had resolved completely and she was considerably less fatigued. At this time the ESR was $6 \mathrm{~mm} / \mathrm{lst} \mathrm{h}$ and CRP $2 \mathrm{mg} / \mathrm{l}$.

\section{DISCUSSION}

Although a thorough history and examination can allow the diagnosis of Takayasu's arteritis to be made, confirmation and assessment of the extent of the disease depends on arteriography. Classically, the aortogram shows both dilatation and stenosis of large arteries, but this is not always the case. However, unusually in this patient the diagnosis was suggested by CT scanning demonstrating aortitis. Recent published reports have shown that CT can be very useful in detecting Takayasu's arteritis because it shows such details as wall thickening and perivascular oedema, which cannot be detected by arteriography. ${ }^{1-3} \mathrm{CT}$ is also useful as a non-invasive means of monitoring patients with Takayasu's arteritis who are undergoing treatment, to examine disease resolution or progression.

\section{Authors' affiliations}

A Muthumala, D S Appleton, J S H Gaston, Departments of

Rheumatology and Radiology, Addenbrooke's Hospital, Hills Road, Cambridge CB2 2QQ, UK

Correspondence to: Professor J S H Gaston: jshg2@medschl.cam.ac.uk

Accepted 4 April 2002

\section{REFERENCES}

1 Zlatkin S, Aamar S, Specter G, Leibowitz D, Simanovsky N, Yeshurun D, et al. Takayasu's arteritis identified by computerized tomography: revealing the submerged portion of the iceberg? Isr Med Assoc 1999; 1:245-9.

2 Yamada I, Nakagawa T, Himeno Y, Numano F, Shibuya H. Takayasu arteritis: evaluation of the thoracic aorta with CT angiography. Radiology 1998;209: 103-9

3 Park JH. Conventional and CT angiographic diagnosis of Takayasu arteritis. Int J Cardiol 1996;54(suppl):S165-71.

\section{Is soluble CD44 variant isoform 5 useful as a predicting factor and a parameter for long term observation in rheumatoid arthritis?}

\section{Skoumal, G Kolarz, G Haberhauer, J Feyertag, A Wottawa}

r $\mathrm{n}$ addition to its widespread expression, CD44 is a homing receptor for human $\mathrm{T}$ cells and an adhesion molecule in cell-cell and cell-matrix interaction. ${ }^{12} \mathrm{CD} 44$ is a receptor for hyaluronan and other extracellular matrix and cell surface proteins. CD44 has been characterised in detail on lymphocytes, macrophages, fibroblasts, epithelial cells, and keratinocytes. It is part of the regulation of immune mediated inflammation. The binding of CD44 leads to lymphocyte homing, lymphocyte binding to high endothelial venules, myelopoiesis, lymphocyte activation, natural killer target lysis, B cell lymphopoiesis, cell adhesion, inflammation, and tumour dissemination. ${ }^{3}$ Binding of CD44 monoclonal antibodies or hyaluronan induces intracellular signals that enhance T lymphocyte mitogenesis and releases cytokines (interleukin 1, tumour necrosis factor $\alpha$ ) from macrophages. Furthermore, it has been suggested that extravasation of $\mathrm{T}$ lymphocytes is mediated by CD44.

The soluble CD44 isoform variant 5 (sCD44v5) was found to be increased in the serum of patients with active rheumatoid arthritis (RA). ${ }^{45}$ So far no longitudinal studies have been carried out.
We examined whether sCD44v5 correlates with inflammation or joint destruction, or both, in the long term treatment of patients with RA.

\section{METHODS AND RESULTS}

Serum levels of sCD44v5 were measured in 81 patients with RA according to the criteria of the American College of Rheumatology, who were admitted at least three times during an observation period of 10 years (table 1). A commercially available enzyme linked immunosorbent assay (ELISA), developed by Bender-Med Systems, Vienna, was used to measure sCD44v5. The influence of rheumatoid factor (RF) on the measurements of sCD44v5 was ruled out by dilution experiments. The results of sCD44v5 at the first visit and the area under the curve as measure for the long term course were compared with the disease activity score, 28 joint count, 30 swollen joint count, Ritchie index, proximal interphalangeal score, Stoke index, Larsen score, Steinbrocker stage, C reactive protein, erythrocyte sedimentation rate, RF, and treatment with disease modifying antirheumatic drugs (DMARDs) as well. 
Table 1 Clinical data of 81 patients (57 female, 24 male) at the first visit

\begin{tabular}{lllll}
\hline & Mean & SD & Minimum & Maximum \\
\hline Age at onset (years) & 48.6 & & 18.0 & 72.0 \\
Disease duration (years) & 11.6 & & 0.9 & 58.0 \\
Observation period (years) & 6.7 & & 2.7 & 10.0 \\
ESR (mm/1 st h) & 35.2 & 22.3 & 4.0 & 108.0 \\
sCD44v5 (ng/ml) & 41.7 & 27.6 & 6.3 & 160.8 \\
CRP (mg/l) & 29.8 & 27.8 & 0.0 & 120.0 \\
DAS & 3.9 & 1.1 & 0.8 & 7.1 \\
PIP & 1.8 & 3.0 & 0.0 & 10.0 \\
RF (U/ml) & 272.8 & 764.6 & 0.0 & 6634.0 \\
Ritchie index & 14.1 & 10.2 & 0.0 & 41.0 \\
Steinbrocker stage & 2.3 & 0.8 & 1.0 & 4.0 \\
Stoke & 6.4 & 3.4 & 1.0 & 17.0 \\
28JC & 17.2 & 11.9 & 0.0 & 55.0 \\
3OSJC & 8.4 & 6.6 & 0.0 & 28.0 \\
Larsen score & 50.8 & 43.9 & 0.0 & 178.0 \\
\hline
\end{tabular}

$E S R$, erythrocyte sedimentation rate; $\mathrm{s} C D 44 v 5$, soluble $C D 44$ variant isoform 5 ; $C R P, C$ reactive protein; DAS, disease activity score; PIP, proximal interphalangeal score; RF, rheumatoid factor; $28 \mathrm{JC}, 28$ joint count; 3OSJC, 30 swollen joint count.

Table 2 Spearman correlation coefficient of sCD44v5 at visit 1 and AUC sCD44v5 compared with clinical and laboratory parameters

\begin{tabular}{llllllll}
\hline & RF & ESR & CRP & Stoke & 28JC & 30SJC & $\Delta$ Larsen \\
\hline CC & 0.6068 & 0.1201 & 0.0448 & 0.0010 & -0.1123 & -0.1238 & -0.0470 \\
Visit 1 CD44 & 0.0001 & 0.2883 & 0.6910 & 0.9929 & 0.3181 & 0.2706 & 0.6767 \\
CC & 0.2265 & 0.1118 & 0.2152 & 0.1229 & -0.1101 & -0.1653 & -0.0013 \\
AUC CD44 & 0.0419 & 0.3235 & 0.0537 & 0.2742 & 0.3278 & 0.1402 & 0.9906 \\
\hline
\end{tabular}

CC, correlation coefficient; ESR, erythrocyte sedimentation rate; $A U C$, area under the curve; RF, rheumatoid factor; ESR, erythrocyte sedimentation rate; CRP, C reactive protein; 28JC, 28 joint count; 30 SJC, 30 swollen joint count.

When appropriate, results were analysed by repeated measures analysis of variance, general linear model, and Spearman's correlation coefficient.

We detected raised serum levels of sCD44v5 in 50/356 measurements, with a range from 58.4 to $312.9 \mathrm{ng} / \mathrm{ml}$. The mean sCD $44 \mathrm{v} 5$ was $42.3 \mathrm{ng} / \mathrm{ml}$. We could not find a significant correlation between SCD44v5 and the clinical and laboratory data of visit 1, except for a correlation with RF (table 2). Increased Steinbrocker stages and Larsen scores did not show a correlation with sCD44v5. To demonstrate sCD44v5 as a predicting factor we therefore correlated the sCD44v5 values of the first visit with $\Delta$ Larsen, but the result was not significant.

\section{DISCUSSION}

SCD44v5 is described as a measure of inflammation and as an indicator for treatment response in RA. ${ }^{6}$

We aimed at examining whether SCD44v 5 might be useful as a predicting factor and measure of treatment response to different DMARDs. Although sCD44v5 is known to be raised in patients with rheumatoid flare, such a correlation could not be shown in our study of patients with weakly to moderately inflamed disease. Soluble CD44 seems to be raised only in severe inflammation. ${ }^{7}$ We found no evidence that sCD44v5 might be a predicting factor. In particular, no significant difference was found between sCD44v5 and Steinbrocker stages or the Larsen score.

Earlier studies have shown that SCD44v5 has an important role as an indicator of inflammation in RA, but in our long term study sCD44v5 had no clinical relevance.

\section{Authors' affiliations}

M Skoumal, G Kolarz, A Wottawa, Institute for Rheumatology in cooperation with the Donau Universität Krems, Marchetstrasse 78, 2500 Baden, Austria

G Haberhaver, J Feyertag, 5th Department of Internal Medicine with Rheumatology, Wilhelminenspital der Stadt Wien, Montleartstrasse 37 1160 Vienna, Austria

Correspondence to: Dr M Skoumal, Rheumasonderkrankenanstalt der SVA gewerbliche Wirtschaft, Adolfine Malchergasse 1, 2500 Baden, Austria; martin.skoumal@al.net

\section{Accepted 16 April 2002}

\section{REFERENCES}

1 Haynes BF, Hale LP, Patton KL, Martin ME, McCallum RM. Measurement of an adhesion molecule as an indicator of inflammatory disease activity. Up-regulation of the receptor for hyaluronan (CD44) in rheumatoid arthritis. Arthritis Rheum 1991;34:1434-41.

2 Haynes BF, Telen M, Hale LP, Denning SM. CD44-A molecule involved in leukocyte adherence and T-cell activation. Immunol Today $1989 ; 10: 423-8$

3 Fox SB, Fawcette J, Jackson DG, Collins I, Gatter KG, Harris AL, et al. Normal human tissues in addition to some tumors, express multiple different CD44 isoforms. Cancer Res 1994;54:4539-46.

4 Haberhauer G, Kittel EM. Soluble CD44-isoform variant 5 (sCD44v5): a new serum marker in rheumatoid arthritis? J Rheumatol 1998;25:1442-4

5 Kittel EM, Haberhauer G, Ruckser R, Selleny S, Rech-Weichselbraun I, Hinterberger W, et al. Serum levels of soluble CD44 variant isoforms are elevated in rheumatoid arthritis. Rheumatol Int 1997;16:181-6.

6 Feyertag J, Haberhauer G, Skoumal M, Kittl EM, Bauer K, Dunky A. Serumspiegel löslicher CD44-Isoform-Variante 5 von Patienten mit seropositiver Rheumatoid-Arthritis unter Cyclosporin-A Therapie. Acta seropositiver Rheumatoid-Arthritis Unter

7 Kelleher D, Murphy A, Hall N, Ormary MB, Kearns G, Long A, et al. Expression of CD44 on rheumatoid synovial fluid lymphocytes. Ann Rheum Dis 1995;54:566-70. 